\title{
Miquelianin inhibits allergic responses in mice by suppressing CD4+ T cell proliferation
}

\author{
Dae Woon Choi ${ }^{1}$, Sun Young Jung ${ }^{1}$, So-Young Lee ${ }^{1}$, and Hee Soon Shin ${ }^{1}$ \\ ${ }^{1}$ Korea Food Research Institute
}

August 28, 2020

\begin{abstract}
Background. Allergic disorders such as atopic dermatitis (AD), allergic rhinitis, asthma, and food allergy show a predominant immune response by type 2 helper $\mathrm{T}$ (Th2) cells. We previously revealed that Rosae multiflorae fructus extract ameliorates ovalbumin-induced allergic rhinitis symptoms in a mouse model and identified miquelianin (quercetin 3-O-glucuronide, MQL) as the active compound. However, it is unknown if MQL affects allergic diseases or regulates Th2 immune responses. In this study, we investigated the anti-allergic effects of MQL. Methods. To investigate anti-allergic effects of MQL, we used an ovalbumin (OVA)-induced Th2-dominant mouse model and assessed cytokine production, cell proliferation, and upstream signaling pathways. Results. Oral administration of MQL suppressed the production of Th2 cytokines and IL-2, and cell proliferation. Additionally, heme oxygenase-1 (HO-1) expression was increased by MQL in splenocytes. In ex vivo studies using splenocytes and CD4+ T cells from mice, MQL suppressed Th1- and Th2-related immune responses by inhibiting CD4+ T cell proliferation. Furthermore, MQL increased HO-1 expression by activating the C-Raf -ERK1/2-NRF2 pathway by inducing the generation of intracellular reactive oxygen species in CD4 $\mathrm{T}$ cells. Finally, to verify the effects of MQL in vivo during an allergic disorder, we used a trimellitic anhydride-induced AD-like mouse model. Both topical treatment and oral administration of MQL ameliorated AD symptoms by suppressing Th2 immune responses, including serum IgE production Th2 cytokine production in draining lymph nodes. Conclusions. MQL can be used as a therapeutic agent for CD4+ T cell-mediated diseases such as allergic diseases.
\end{abstract}

\section{Abbreviations}

AD, atopic dermatitis; APCs, antigen-presenting cells; Con A, concanavalin A; DC, dendritic cells;Dex, dexamethasone; DLNs , draining lymph nodes; $\mathbf{\Phi} \boldsymbol{\varsigma} \mathbf{\varepsilon P I}$, Fcع receptor I; HO-1, heme oxygenase-1;IFN , interferon; Ig , immunoglobulin; IL,interleukin; Keap1, Kelch-like ECH-associated protein 1;MAPKs, mitogen-activated protein kinases; NAC,N-acetylcysteine; NRF2, nuclear factor erythroid 2-related factor 2; OVA, ovalbumin; PI, propidium iodide;STAT, signal transducer and activator of transcription;Th, T helper; TMA, trimellitic anhydride; TNF, tumor necrosis factor

\section{Introduction}

Allergic diseases such as allergic rhinitis, asthma, food allergy, atopic dermatitis, allergic contact dermatitis, and anaphylaxis contribute to the rising cost of health care and cause a lower quality of life. Allergy is characterized by immune responses by antigen-specific type 2 helper T (Th2) cells that are involved in the development of antigen-specific immunoglobulin E ( $\operatorname{IgE}$ ) responses produced following class switching of B cells ${ }^{1}$. $\mathrm{T}$ cell receptors (TCRs) in naïve $\mathrm{CD} 4^{+} \mathrm{T}$ cells recognize antigens upon co-stimulation by CD28 when contacting antigen-presenting cells (APCs). Antigen presentation to naïve CD4 ${ }^{+} \mathrm{T}$ cells induces their differentiation into effector and memory $\mathrm{T}$ cells, and triggers clonal expansion. Activated $\mathrm{T}$ cells produce IL-2, which stimulates $\mathrm{T}$ cell proliferation, by autocrine or paracrine signaling ${ }^{2,3}$. Naïve $\mathrm{CD} 4^{+} \mathrm{T}$ cells can differentiate into at least four subtypes including Th1, Th2, Th17, and induced regulatory T (iTreg) cells ${ }^{4}$. 
Among these subsets of CD4 ${ }^{+} \mathrm{T}$ cells, Th2 cells are characterized by their production of interleukin (IL)-4, IL-5, and IL-13, and stimulate B cell class switching to produce antigen-specific $\operatorname{IgE}{ }^{5}$.

Heme oxygenases (HO) are essential enzymes that catabolize heme into iron (Fe), biliverdin, and carbon monoxide (CO). Three isoforms of HO exist: the inducible form (HO-1) and constitutive forms (HO-2 and HO-3). In particular, HO-1 is an inducible enzyme expressed in mammalian tissues and plays a cytoprotective role $\mathrm{e}^{6-8}$. It is well established that oxidative stress activates the nuclear factor erythroid 2-related factor 2 (NRF2) pathway resulting in HO-1 expression. In turn, HO-1 plays an essential role in maintaining intracellular homeostasis against excess reactive oxygen species (ROS) generated by redox signaling ${ }^{9}$, and protects cells against oxidative stress and inflammation ${ }^{10,11}$. In addition, HO- 1 can regulate cell proliferation by arresting the cell-cycle by generating $\mathrm{CO}^{12,13}$. Previous studies investigating regulatory effects of HO-1 on $\mathrm{T}$ cells revealed that $\mathrm{CO}$ generated by $\mathrm{HO}-1$ also suppresses $\mathrm{CD} 4^{+} \mathrm{T}$ cell proliferation by inhibiting IL-2 production ${ }^{14}$, and $\mathrm{CO}$ exposure suppresses proliferation and activation of $\mathrm{T}$ cells ${ }^{15,16}$. Phytochemicals obtained through fruit and vegetable consumption have protective effects against diverse diseases by inducing HO-1 expression by activating the NRF2 pathway ${ }^{17}$. Among these phytochemicals, quercetin, the aglycone of miqeulianin, has been reported to protect cells from oxidative stress and inflammation by generating HO- $1^{18,19}$, and recently, it was reported that quercetin suppresses T cell proliferation via HO-1 generation ${ }^{20}$.

In a previous study, we revealed that Rosae multiflorae fructus extract ameliorates OVA-induced allergic rhinitis symptoms in a mouse model, and identified miquelianin as the active compound of Rosae multifloraefructus ${ }^{21}$. Miqeulianin (quercetin 3-O -glucuronide, MQL), one of the flavonoids, is a quercetin glycoside. MQL has been reported to have antioxidant ${ }^{22}$, antidepressant ${ }^{23}$, and antiproliferative effects ${ }^{24}$. However, it is unknown if MQL affects allergic diseases or regulates Th2 immune responses. Thus, in this study, we examined the effect of MQL on a TMA-induced AD-like mouse model, and investigated the mechanisms by which MQL regulates Th2-related immune responses in vitro .

\section{Materials and Methods}

We provide full methods (detailed explanations of materials and methods) as supplementary materials in online supporting information as follows:

\subsection{Materials}

\subsection{Animals}

2.3. Induction of AD-like symptoms by TMA ${ }^{25,26}$

2.4. OVA-induced allergic mouse model

2.5. Culture of draining lymph node (DLN) cells and splenocytes

2.6. In vitro assay using mouse splenocytes immunized by OVA

2.7. $\mathrm{CD}_{4}^{+} \mathrm{T}$ cell isolation and proliferation assay

2.8. $\mathrm{HO}-1$ and NRF2 detection in $\mathrm{CD}_{4}^{+} \mathrm{T}$ cells

2.9. Cell cycle analysis

2.10. Reactive oxygen species (ROS) detection

2.11. Measurement of cytokines and serum IgE using ELISA

2.12. Western blotting

2.13. Statistical analysis

\section{Results}

3.1. Effect of oral MQL administration on OVA-induced allergy 
In this study, we examined whether oral administration of MQL affects Th2-related allergic immune responses using an OVA-induced mouse model of allergy. The mice were sensitized and immunized by OVA and orally administered MQL for 2 weeks. We investigated typical allergic responses such as production of IgE and Th2-mediated cytokines including IL-4, IL-5, and IL-13. We found that levels of serum IgE and splenic Th2 cytokines were significantly suppressed by oral administration of MQL(Fig. 1B-E) .

In our previous study, we showed that Rosae multiflorae fructus extract containing MQL suppressed Th2related immune responses by inhibiting the proliferation of immune cells via up-regulation of HO-1 expression. Similarly, it has been reported that increased HO-1 expression in $\mathrm{CD}_{4}^{+} \mathrm{T}$ cells suppressed proliferation by inhibiting IL-2 production ${ }^{7}$. Based on these studies, we measured IL-2 production and proliferation of splenocytes, and confirmed that these were significantly reduced in MQL-administered groups (Fig. 1F and 1G) . Furthermore, we found that splenocytes in MQL-administered groups had increased HO-1 expression compared to the sham group (Fig. 1H) .

\subsection{Immunomodulatory effects of $M Q L$ on splenocytes from $B A L B / c$ mice immunized by $O V A$}

$\mathrm{BALB} / \mathrm{c}$ mice were immunized twice with OVA and alum, then splenocytes were isolated. Using this ex vivo system, we investigated whether MQL treatment regulates allergic immune responses by suppressing cell proliferation via increased HO-1 expression.

OVA-induced Th1- (IFN- $\gamma$ ) and Th2-related cytokines (IL-4, IL-5, and IL-13) were significantly suppressed by MQL treatment (Fig. 2A-D) . Next, to investigate whether the immunomodulatory effects of MQL were a consequence of decreased cell proliferation, we measured proliferation and IL-2 production. Notably, MQL treatment suppressed IL-2 production as well as splenocyte proliferation (Fig. $\mathbf{2 F}$ and $\mathbf{G}$ ) . To further characterize these T cell subsets, we analyzed Th1- (STAT1) and Th2-associated transcriptional factor (STAT6), as well as HO-1. Figures $\mathbf{2 H}$ and I show that STAT6 and STAT1 phosphorylation were reduced by MQL treatment, whereas HO-1 expression was increased by MQL. Interestingly, however, the Th1-related cytokine IL-12 was increased by MQL treatment (Fig. 2E). These results indicate that MQL treatment largely inhibits Th1- and Th2-related immune responses via reduction of cell proliferation induced by HO-1 up-regulation.

\subsection{Effects of $M Q L$ on $\mathrm{CD}_{4}^{+} \mathrm{T}$ cell proliferation and $\mathrm{HO}-1$ expression}

IL-2 is an essential factor for CD4 ${ }^{+} \mathrm{T}$ cell proliferation and is produced following antigen recognition by TCR with co-stimulation by CD28. IL-2 then binds its receptor via paracrine and autocrine mechanisms and causes clonal expansion of $\mathrm{CD} 4^{+} \mathrm{T}$ cells ${ }^{3}$. In this experiment, naïve $\mathrm{CD} 4^{+} \mathrm{T}$ cells were isolated and stimulated with anti-CD3 (TCR stimulation) and anti-CD28 antibodies (co-stimulation). We then investigated the effects of MQL on $\mathrm{CD}^{+} \mathrm{T}$ cell proliferation and IL-2 production, and found that MQL treatment suppressed both proliferation and IL-2 production in a dose-dependent manner (Fig. 3A and B) .

p21 (known as p21 WAF1/Cip1) is a cyclin-dependent kinase (CDK) inhibitor and arrests cell cycle progression in the G1 phase ${ }^{27}$. Furthermore, it was reported that up-regulation of HO-1 is able to increase $=$ p21 levels, resulting in reduced cell proliferation ${ }^{12}$. Therefore, we investigated whether MQL affects the cell cycle in $\mathrm{CD}^{+}{ }^{+} \mathrm{T}$ cells, and observed that MQL treatment increased p21 levels and arrested the cell cycle at the G1 stage compared with untreated CD4 ${ }^{+} \mathrm{T}$ cells (Fig. 3C and D) .

Nrf2 is a transcription factor of HO-1 that is sequestered in the cytoplasm by binding with Kelch-like ECH-associated protein 1 (Keap1). When Nrf2 is released from Keap1, it translocates into the nucleus then increases transcription of the HO-1 gene by binding to its antioxidant response element (ARE) $)^{28,29}$. We thus investigated Nrf2 translocalization following MQL and found that NRF2 nuclear translocation and consequent HO-1 were increased by MQL in $\mathrm{CD} 4^{+} \mathrm{T}$ cells (Fig. 3E and F) . Collectively, these results demonstrate that MQL upregulates p21, arrests the cell cycle, and activates the NRF2-HO-1 pathway, resulting in reduced $\mathrm{CD} 4^{+} \mathrm{T}$ cell proliferation.

3.4. Effects of $M Q L$ on MAP kinase signaling pathways 
Next, to investigate MAP kinases upstream of MQL-induced HO-1 expression, we cultured $\mathrm{CD}^{+}{ }^{+} \mathrm{T}$ cells with U0126 (ERK inhibitor), SB20350 (p38 inhibitor), or SP600125 (JNK inhibitor) in the presence of MQL. As a result, MQL-induced HO-1 expression was most significantly reduced by U0126 treatment compared with the other inhibitors (Fig. 4A) . To explore this further, we measured ERK1/2, p38, and JNK activation in the presence or absence of $\mathrm{T}$ cell stimulation (anti-CD3/CD28 antibodies). Consistent with the previous finding, MQL dose-dependently increased the phosphorylation of ERK, but not p38 or JNK (Fig. 4B and C) .

The Ras-Raf-MEK-ERK signaling pathway plays a crucial role in gene expression related to cell growth, proliferation, differentiation, and survival ${ }^{30,31}$. Ras proteins are small GTPases that can activate Raf-MEKERK signaling ${ }^{32}$. GTP-bound Ras interacts with the Raf family (A-Raf, B-Raf, and C-Raf), inducing Raf

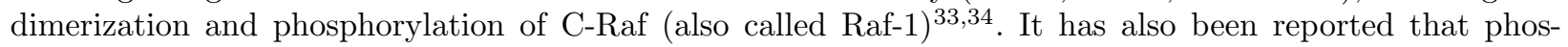
phorylation of C-Raf (Ser338) can induce ERK activation in lymphocytes such as T cells and B cells ${ }^{35}$. Therefore, we hypothesized that C-Raf could be the signal upstream of ERK, and indeed found that MQL treatment induced phosphorylation of C-Raf (Ser338) (Fig. 4D) .

\subsection{Effects of $M Q L$ on ROS generation in $\mathrm{CD}_{4}^{+} \mathrm{T}$ cells}

Phytochemicals have been well-known as antioxidants that can directly scavenge ROS, and are used to protect against inflammation ${ }^{36,37}$. Whereas phytochemicals can generate appropriate intracellular ROS, resulting in up-regulation of HO-1 expression ${ }^{38}$. Furthermore, intracellular ROS have been linked to ERK1/2 as cAMTmediated ROS production can induce ERK1/2 phosphorylation via Ras activation ${ }^{39}$. Thus, we investigated intracellular ROS generated by MQL in CD4 ${ }^{+} \mathrm{T}$ cells using DCFH-DA or MitoSOX ${ }^{\mathrm{TM}}$ Red, and found that MQL increased intracellular and mitochondrial ROS levels (Fig. 5A and B). Next, to investigate effects of intracellular ROS generated by MQL on the C-Raf-ERK1/2 signaling pathway, CD4 ${ }^{+} \mathrm{T}$ cells were cultured with MQL in the presence and absence of the antioxidant N-acetylcysteine (NAC). We found that MQLinduced C-Raf and ERK1/2 phosphorylation, as well as HO-1 expression, were suppressed by NAC treatment (Fig. 5C and D) . Taken together, these results suggest that MQL-induced ROS mediate Ras-Raf-ERK activation and HO- 1 expression in $\mathrm{CD} 4^{+} \mathrm{T}$ cells.

\subsection{Effects of topical and oral MQL administration on TMA-induced AD symptoms}

To evaluate the effects of MQL on Th2-mediated allergic diseases, we used a TMA-induced AD-like mouse model. Since AD symptoms have been known to occur through both external and internal factors, we administered MQL treatment either topically or orally. After topical treatment of MQL, ear thickness and infiltration of inflammatory cells were reduced compared to the sham group (Fig. 6B and C) . Furthermore, serum IgE levels were reduced in MQL10 group (Fig. 6D). Next, to investigate the effects of MQL on T cell-mediated immune responses, we measured Th1 (IL-12 and IFN- $\gamma$ ) and Th2 (IL-13) cytokine production in the culture supernatant of DLNs and found that IL-13 and IFN- $\gamma$ production were significantly reduced by MQL treatment, but IL-12 was not changed (Fig. 6E-G) .

Next, we investigated effect of oral MQL administration on TMA-induced AD. Similar to topical administration, oral MQL administration ameliorated AD symptoms such as ear swelling and infiltration of inflammatory cells in ear (Fig. 6I and $\mathbf{J}$ ), and TMA-induced serum IgE production was decreased by MQL compared with the sham group(Fig. 6K) . In DLNs, oral administration of MQL reduced IL-13 production and increased IL-12 (Fig. 6L and N). These results suggest that either topical or oral administration of $\mathrm{MQL}$ is a possible treatment to attenuate the symptoms of $\mathrm{AD}$.

\section{Discussion}

To investigate effects of MQL on allergic immune responses, we used an OVA-induced allergic mouse model, and showed that MQL suppresses Th2-related immune responses such as serum IgE production and Th2 cytokine production by splenocytes. In our previous studies, we revealed that MQL was one of active compounds in Rosae multiflorae fructus extract, which can ameliorate asthma, rhinitis, and food allergies ${ }^{21,40}$. Furthermore, Nguyen et al . reported that Rosae multiflorae fructus has an anti-allergic effect by suppress- 
ing antigen-specific $\mathrm{T}$ cell activation and proliferation in vivo ${ }^{41}$. Our results in vivo study also suggest that MQL suppresses splenocyte proliferation and IL-2 production, thereby inhibiting Th2-related immune responses. Therefore, we focused on $\mathrm{CD}^{+} \mathrm{T}$ cells and investigated the anti-allergic mechanisms of MQL.

Th2-dominant responses, showing increased Th2 (IL-4, IL-5, and IL-13) cytokines and IgE production, are characteristic immune responses in patients with allergic diseases such as food allergy, asthma, and $\mathrm{AD}^{42-44}$. We previously reported some strategies to treat allergic diseases ${ }^{45-47}$. The first involves regulating the Th1/Th2 immune balance by suppressing excessively induced Th2-mediated immune responses or increasing Th1-related immune responses ${ }^{4-50}$. However, here we confirmed that MQL treatment does not increase the Th1-associated cytokine IFN- $\gamma$. Thus, we focused on $\mathrm{T}$ cell proliferation as reducing $\mathrm{T}$ cell clonal expansion and differentiation represents an alternative way to manage allergic diseases ${ }^{2}$. Mechanisms for suppressing $\mathrm{T}$ cell proliferation are typically inducing regulatory $\mathrm{T}$ cells (Treg) or up-regulating HO-1 expression. When we investigated the effects of MQL on Treg induction, MQL treatment did not increase $\mathrm{CD} 4^{+} \mathrm{Foxp}^{+} \mathrm{T}$ cell populations (data not shown). Therefore, in the present study, we investigated the effects of MQL on Th2-dominant allergic immune responses and mechanisms involved in HO-1 expression.

HO-1 is known to have various physiological functions including a protective effect against oxidative stress $^{12,13}$. In particular, it was reported that up-regulation of $\mathrm{HO}-1$ in $\mathrm{CD} 4^{+} \mathrm{T}$ cells suppresses their proliferation by inhibiting IL-2 production ${ }^{7}$. Similarly, our results showed that MQL suppresses CD4 ${ }^{+} \mathrm{T}$ cell proliferation and IL-2 production induced by anti-CD3/CD28 antibody stimulation, while HO-1 expression was increased. Based on these results, we hypothesize that MQL may be able to suppress the CD4 ${ }^{+}$ $\mathrm{T}$ cell-mediated immune responses by inhibiting proliferation of $\mathrm{CD} 4^{+} \mathrm{T}$ cells via up-regulation of HO-1. Furthermore, we speculate that HO-1 is a key regulator of $\mathrm{CD}^{+} \mathrm{T}$ cell proliferation.

Up-stream signals of HO-1 have been reported by many previous studies. Notably, Nrf2, which is normally repressed by Keap1, translocates to the nucleus upon activation and binds to ARE sequences of the HO-1 gene. Especially, about the regulation of HO-1 on cell proliferation, activation of MAPKs (ERK, JNK, and p38) as up-stream signals of Nfr2 plays as factors, which are able to regulate cell proliferation. However, the specific MAPKs involved depend on the administered compounds. For example, it was reported that quercetin enhances Nrf2/HO-1 activity via both ERK and p38 signaling pathways ${ }^{51,52}$ and suppresses $\mathrm{T}$ cell proliferation by enhancing HO-1 expression ${ }^{20}$. Quercetin-3-O- $\beta$ - D-glucuronopyranoside, also known as isoquercitrin, can also up-regulate HO-1 expression via ERK pathways ${ }^{53}$. Although in a different cell type, in a recent study, Lee et al. revealed that MQL up-regulates HO-1 expression via the Nrf2 pathway in human hepatoma cells (HepG2) but does not activate nuclear factor-kappa B $(\mathrm{NF}-\chi \mathrm{B})^{54}$. In this study, we found that MQL activated Nrf2-HO-1 signals through phosphorylation of ERK in $\mathrm{CD} 4^{+} \mathrm{T}$ cells. In experiments using MAPK inhibitors, we confirmed that U0126 (ERK inhibitor) most significantly suppressed HO-1 expression, and MQL strongly increased ERK phosphorylation in CD4 ${ }^{+}$T cells. Although treatment with SB20350 (p38 inhibitor) suppressed HO-1 expression, it was relatively weak compared with the effect of U0126. Moreover, p38 phosphorylation was not detected following MQL treatment. Therefore, our results demonstrate that ERK activation is upstream of MQL-induced HO-1 expression in $\mathrm{CD} 4^{+} \mathrm{T}$ cells.

Ras is a small GTP-binding protein with three isoforms (H-Ras, K-Ras, and N-Ras), and controls growth via ERK activation and other intracellular signaling pathways ${ }^{55}$. Membrane-bound Ras (GTP-bound active form) can activate Raf by recruiting Raf and promoting the formation of B-Raf /C-Raf complexes or homodimers. Activated Raf protein can then induce phosphorylation of ERK1 $/ 2^{34,56}$. Previous studies have reported that HO-1 expression can be up-regulated by activating the Ras-Raf-ERK signaling pathway ${ }^{57,58}$. Based on these findings, we investigated whether MQL-induced HO-1 up-regulation was associated with C-Raf phosphorylation. Our results showed that MQL could induce phosphorylation of C-Raf in CD4 ${ }^{+} \mathrm{T}$ cells, indicating that C-Raf could be a potential up-stream signal of the ERK-Nrf2 signaling pathway.

ROS such as superoxide anion radicals (. $\left.2^{-}\right)$, hydroxyl radicals $(\cdot \mathrm{OH})$, and hydrogen peroxide $\left(\mathrm{H}_{2} \mathrm{O}_{2}\right)$ are constantly produced as a byproduct of mitochondrial oxidative metabolism. Excessively generated ROS, however, can induce oxidative stress, which underlies various diseases, while normal ROS levels can regulate cell growth by modulating proliferation and differentiation. Specifically, ROS activate cellular pathways 
such as MAPK, JAK/STAT, Nrf2, and NF- $\chi$ B signals ${ }^{59-61}$. Furthermore, intracellular ROS are known to induce HO-1 expression ${ }^{62,63}$. Consistent with our results, it was reported that intracellular ROS activates the Raf-MEK-ERK signaling pathways ${ }^{64}$ and could induce ERK1/2 phosphorylation by activating $\operatorname{Ras}^{39,65}$. Importantly, flavonoids are antioxidant secondary phenolic metabolites naturally produced in fruits and vegetables, and are able to against oxidative stress ${ }^{66}$. However, the flavonoids can also increase intracellular ROS levels as prooxidants. For example, McNally et al, revealed that curcumin increases HO-1 expression via ROS generation ${ }^{67}$. In addition, it has been reported that quercetin can also act as a prooxidant capable of producing intracellular $\mathrm{ROS}^{37,68}$. In this study, we found that MQL induces ROS production in CD4 ${ }^{+} \mathrm{T}$ cells, which enhances HO-1 expression via Raf-ERK activation. Consequently, this leads to suppression of IL-2 production and $\mathrm{CD}^{+}{ }^{+} \mathrm{T}$ cell proliferation.

TMA as a hapten has been known to induce allergic AD by evoking Th2-dominant immune responses in mice $^{26,69-71}$. Haptens act as antigens by generating hapten-protein complexes through conjugation with self-proteins then activate adaptive immune responses when recognized by APCs such as DCs ${ }^{71}$. Langerhans cells, which are DCs that reside in the epidermis, induce naïve $\mathrm{CD} 4^{+} \mathrm{T}$ cell differentiation by presenting antigens after migrating into $\mathrm{T}$ cell-rich areas, such as the paracortex of the DLNs ${ }^{72}$. To characterize the effects of MQL on a TMA-induced AD-like mouse model, we administered MQL either orally or topically, since both oral and topical therapies are effective for treating AD. Considering that this was a disease model, we used a higher dosage of MQL (4 and $10 \mathrm{mg} / \mathrm{kg}$ ) than in the OVA-induced Th2-dominant mouse model (MQL, 2 and $4 \mathrm{mg} / \mathrm{kg}$ ). Our results revealed that AD symptoms such as ear swelling, tissue infiltration of inflammatory cells, and IgE production were ameliorated by MQL in both topical and oral treatments. Interestingly, serum IgE levels were strongly reduced by oral administration of MQL compared with topical administration, possibly because of IgE production involves a systemic immune response. However, in DLNs, which represent peripheral immune responses, IL-13 levels induced by TMA were dramatically reduced by topical treatment of MQL compared with oral administration. These results indicate that MQL may be effective as an oral or topical drug depending on the internal or external causes of atopic dermatitis. Further anti-proliferative effects of MQL were seen in allergic mouse models as Th2 (IL-13) and Th1 (IFN- $\gamma$ ) cytokines decreased, but not IL-12 (cytokine derived from APC). Fig. 6 shows that IFN- $\gamma$ is suppressed by MQL topical treatment, but not IL-12, while oral administration of MQL did not affect IFN- $\gamma$ production but increased IL-12 production. More evidently, IFN- $\gamma / \mathrm{IL}-12$ ratios showed that MQL treatment decreases IFN- $\gamma$ production compared with the TMA alone group as follows: Ratio of IFN- $\gamma / \mathrm{IL}-12$ in the naïve group (oral, 1.3; topical, 1.7), TMA-induced AD group (oral, 2.4; topical, 8.9), MQL 4 group (oral, 2.3; topical, 6.5), and MQL 10 group (oral, 2.2; topical, 5.3). Therefore, we believe that MQL has the potential to be developed as a therapeutic agent for AD.

In conclusion, we demonstrated that MQL suppressed Th2-related immune responses by reducing $\mathrm{CD}^{+} \mathrm{T}$ cell proliferation via up-regulation of HO-1 expression. Mechanistically, MQL increased HO-1 expression via activation of the Raf-ERK-Nrf2 pathway and by generating ROS in CD4 ${ }^{+} \mathrm{T}$ cells. Furthermore, we verified that these effects of MQL on CD4 ${ }^{+} \mathrm{T}$ cells leads to alleviated allergic diseases such as an atopic dermatitis in vivo. It is possible that MQL may provide clinical benefits on other allergic and $\mathrm{CD} 4^{+} \mathrm{T}$ cell-mediated diseases. The application MQL on various diseases remains the focus of further studies.

\section{Conflict of interest}

No competing financial interests exist.

\section{References}

1. Ferreira F, Wolf M, Wallner M. Molecular approach to allergy diagnosis and therapy. Yonsei Med $J$. 2014;55(4):839-852.

2. Lanzavecchia A, Sallusto F. Regulation of T cell immunity by dendritic cells. Cell . 2001;106(3):263-266.

3. Stittrich A-B, Haftmann C, Sgouroudis E, et al. The microRNA miR-182 is induced by IL-2 and promotes clonal expansion of activated helper T lymphocytes. Nat Immunol . 2010;11(11):1057-1062. 
4. Zhu J, Paul WE. CD4 T cells: fates, functions, and faults.Blood . 2008;112(5):1557-1569.

5. Akdis M. Immune tolerance in allergy. Curr Opin Immunol . 2009;21(6):700-707.

6. Min K, Lee JT, Joe E, Kwon TK. An I $x \mathrm{~B} \alpha$ phosphorylation inhibitor induces heme oxygenase-1(HO-1) expression through the activation of reactive oxygen species (ROS)-Nrf2-ARE signaling and ROS-PI3K/Akt signaling in an NF-xB-independent mechanism. Cell Signal . 2011;23(9):1505-1513.

7. Pae H-O, Choi B-M, Oh G-S, et al. Roles of heme oxygenase-1 in the antiproliferative and antiapoptotic effects of nitric oxide on Jurkat T cells. Mol Pharmacol . 2004;66(1):122-128.

8. Sikorski EM, Hock T, Hill-Kapturczak N, Agarwal A. The story so far: Molecular regulation of the heme oxygenase-1 gene in renal injury.Am J Physiol Renal Physiol . 2004;286(3):F425-441.

9. Majzunova M, Dovinova I, Barancik M, Chan JYH. Redox signaling in pathophysiology of hypertension. J Biomed Sci . 2013;20:69.

10. Sue Y-M, Cheng C-F, Chang C-C, Chou Y, Chen C-H, Juan S-H. Antioxidation and anti-inflammation by haem oxygenase-1 contribute to protection by tetramethylpyrazine against gentamicin-induced apoptosis in murine renal tubular cells. Nephrol Dial Transplant Off Publ Eur Dial Transpl Assoc - Eur Ren Assoc . 2009;24(3):769-777.

11. Yu W, Zhang X, Wu H, et al. HO-1 Is Essential for Tetrahydroxystilbene Glucoside Mediated Mitochondrial Biogenesis and Anti-Inflammation Process in LPS-Treated RAW264.7 Macrophages. Oxid Med Cell Longev . 2017;2017:1818575.

12. Choi HC, Lee KY, Lee DH, Kang YJ. Heme oxygenase-1 induced by aprotinin inhibits vascular smooth muscle cell proliferation through cell cycle arrest in hypertensive rats. Korean $J$ Physiol Pharmacol Off $J$ Korean Physiol Soc Korean Soc Pharmacol . 2009;13(4):309-313.

13. Duckers HJ, Boehm M, True AL, et al. Heme oxygenase-1 protects against vascular constriction and proliferation. Nat Med . 2001;7(6):693-698.

14. Pae H-O, Oh G-S, Choi B-M, et al. Carbon monoxide produced by heme oxygenase- 1 suppresses $\mathrm{T}$ cell proliferation via inhibition of IL-2 production. J Immunol Baltim Md 1950 . 2004;172(8):4744-4751.

15. Mackern-Oberti JP, Obreque J, Méndez GP, Llanos C, Kalergis AM. Carbon monoxide inhibits T cell activation in target organs during systemic lupus erythematosus. Clin Exp Immunol . 2015;182(1):1-13.

16. Song R, Mahidhara RS, Zhou Z, et al. Carbon monoxide inhibits T lymphocyte proliferation via caspasedependent pathway. J Immunol Baltim Md 1950 . 2004;172(2):1220-1226.

17. Son TG, Camandola S, Mattson MP. Hormetic dietary phytochemicals. Neuromolecular Med . 2008;10(4):236-246.

18. Braun KF, Ehnert S, Freude T, et al. Quercetin protects primary human osteoblasts exposed to cigarette smoke through activation of the antioxidative enzymes HO-1 and SOD-1. ScientificWorldJournal . 2011;11:2348-2357.

19. Kang C-H, Choi YH, Moon S-K, Kim W-J, Kim G-Y. Quercetin inhibits lipopolysaccharide-induced nitric oxide production in BV2 microglial cells by suppressing the NF- $\chi \mathrm{B}$ pathway and activating the Nrf2dependent HO-1 pathway. Int Immunopharmacol . 2013;17(3):808-813.

20. Sugiyama T, Matsushima M, Ohdachi T, et al. Involvement of heme oxygenase- 1 in suppression of $\mathrm{T}$ cell activation by quercetin.Immunopharmacol Immunotoxicol . Published online May 12, 2020:1-11.

21. Bui TT, Kwon D-A, Choi DW, et al. Rosae multiflorae fructus extract and its four active components alleviate ovalbumin-induced allergic inflammatory responses via regulation of Th1/Th2 imbalance in BALB/c rhinitis mice. Phytomedicine Int J Phytother Phytopharm . 2019;55:238-248. 
22. Terao J, Yamaguchi S, Shirai M, et al. Protection by quercetin and quercetin 3-O-beta-D-glucuronide of peroxynitrite-induced antioxidant consumption in human plasma low-density lipoprotein. Free Radic Res . 2001;35(6):925-931.

23. Nahrstedt, Adolf. Antidepressant constituents of Hypericum perforatum. In: Herbal Medicinal Products for the Treatment of Pain. Southern Cross University Press: Lismore; :144-153.

24. Wu Q, Needs PW, Lu Y, Kroon PA, Ren D, Yang X. Different antitumor effects of quercetin, quercetin-3'sulfate and quercetin-3-glucuronide in human breast cancer MCF-7 cells. Food Funct . 2018;9(3):1736-1746.

25. Jung SK, Choi DW, Kwon D-A, Kim MJ, Seong KS, Shon D-H. Oral Administration of Achyranthis radix Extract Prevents TMA-induced Allergic Contact Dermatitis by Regulating Th2 Cytokine and Chemokine Production in Vivo. Mol Basel Switz . 2015;20(12):21584-21596.

26. Schneider C, Döcke W-DF, Zollner TM, Röse L. Chronic mouse model of TMA-induced contact hypersensitivity. J Invest Dermatol . 2009;129(4):899-907.

27. Karimian A, Ahmadi Y, Yousefi B. Multiple functions of p21 in cell cycle, apoptosis and transcriptional regulation after DNA damage.DNA Repair . 2016;42:63-71.

28. Kensler TW, Wakabayashi N, Biswal S. Cell survival responses to environmental stresses via the Keap1Nrf2-ARE pathway. Annu Rev Pharmacol Toxicol . 2007;47:89-116.

29. Loboda A, Damulewicz M, Pyza E, Jozkowicz A, Dulak J. Role of Nrf2/HO-1 system in development, oxidative stress response and diseases: an evolutionarily conserved mechanism. Cell Mol Life Sci CMLS . 2016;73(17):3221-3247.

30. Shaul YD, Seger R. The MEK/ERK cascade: from signaling specificity to diverse functions. Biochim Biophys Acta . 2007;1773(8):1213-1226.

31. Wan PTC, Garnett MJ, Roe SM, et al. Mechanism of activation of the RAF-ERK signaling pathway by oncogenic mutations of B-RAF. Cell . 2004;116(6):855-867.

32. Ramos JW. The regulation of extracellular signal-regulated kinase (ERK) in mammalian cells. Int $J$ Biochem Cell Biol . 2008;40(12):2707-2719.

33. Lavoie H, Therrien M. Regulation of RAF protein kinases in ERK signalling. Nat Rev Mol Cell Biol . 2015;16(5):281-298.

34. Takahashi M, Li Y, Dillon TJ, Kariya Y, Stork PJS. Phosphorylation of the C-Raf N Region Promotes Raf Dimerization. Mol Cell Biol . 2017;37(19).

35. Cantrell D. Signaling in lymphocyte activation. Cold Spring Harb Perspect Biol . 2015;7(6).

36. Fonseca-Silva F, Inacio JDF, Canto-Cavalheiro MM, Almeida-Amaral EE. Reactive oxygen species production and mitochondrial dysfunction contribute to quercetin induced death in Leishmania amazonensis.PloS One . 2011;6(2):e14666.

37. Metodiewa D, Jaiswal AK, Cenas N, Dickancaité E, Segura-Aguilar J. Quercetin may act as a cytotoxic prooxidant after its metabolic activation to semiquinone and quinoidal product. Free Radic Biol Med . 1999;26(1-2):107-116.

38. Ryter SW, Alam J, Choi AMK. Heme oxygenase-1/carbon monoxide: from basic science to therapeutic applications. Physiol Rev . 2006;86(2):583-650.

39. Tai P, Ascoli M. Reactive oxygen species (ROS) play a critical role in the cAMP-induced activation of Ras and the phosphorylation of ERK1/2 in Leydig cells. Mol Endocrinol Baltim Md . 2011;25(5):885-893.

40. Song CH, Bui TT, Piao CH, et al. Rosae Multiflorae Fructus Hot Water Extract Inhibits a Murine Allergic Asthma Via the Suppression of Th2 Cytokine Production and Histamine Release from Mast Cells. 
J Med Food . 2016;19(9):853-859.

41. Nguyen TMN, Lomunova M, Shin HS, Shon D-H, Kim YH, Hwang I. Anti-allergic effects of Rosae multiflorae fructus via inhibition of T cell proliferation and the mast cell function. Appl Biol Chem . 2017;60(4):391402.

42. Van der Pouw Kraan TC, Van der Zee JS, Boeije LC, De Groot ER, Stapel SO, Aarden LA. The role of IL-13 in IgE synthesis by allergic asthma patients. Clin Exp Immunol . 1998;111(1):129-135.

43. Sicherer SH, Sampson HA. Food allergy. J Allergy Clin Immunol . 2010;125(2 Suppl 2):S116-125.

44. Spergel JM, Paller AS. Atopic dermatitis and the atopic march.J Allergy Clin Immunol . 2003;112(6 Suppl):S118-127.

45. Bae M-J, See H-J, Choi G, Kang C-Y, Shon D-H, Shin HS. Regulatory T Cell Induced by Poria cocos Bark Exert Therapeutic Effects in Murine Models of Atopic Dermatitis and Food Allergy. Mediators Inflamm . 2016;2016:3472608.

46. Shin HS, Bae M-J, Choi DW, Shon D-H. Skullcap (Scutellaria baicalensis) extract and its active compound, wogonin, inhibit ovalbumin-induced Th2-mediated response. Mol Basel Switz . 2014;19(2):2536-2545.

47. Shin HS, See H-J, Jung SY, et al. Turmeric (Curcuma longa) attenuates food allergy symptoms by regulating type 1 /type 2 helper T cells (Th1/Th2) balance in a mouse model of food allergy. $J$ Ethnopharmacol . 2015;175:21-29.

48. Lee SY, Huang CK, Zhang TF, et al. Oral administration of IL-12 suppresses anaphylactic reactions in a murine model of peanut hypersensitivity. Clin Immunol Orlando Fla . 2001;101(2):220-228.

49. Romagnani S. Immunologic influences on allergy and the TH1/TH2 balance. J Allergy Clin Immunol . 2004;113(3):395-400.

50. Tournoy KG, Kips JC, Pauwels RA. Counterbalancing of TH2-driven allergic airway inflammation by IL-12 does not require IL-10. J Allergy Clin Immunol . 2001;107(3):483-491.

51. Sun GY, Chen Z, Jasmer KJ, et al. Quercetin Attenuates Inflammatory Responses in BV-2 Microglial Cells: Role of MAPKs on the Nrf2 Pathway and Induction of Heme Oxygenase-1. PloS One . 2015;10(10):e0141509.

52. Yao P, Nussler A, Liu L, et al. Quercetin protects human hepatocytes from ethanol-derived oxidative stress by inducing heme oxygenase-1 via the MAPK/Nrf2 pathways. J Hepatol . 2007;47(2):253-261.

53. Kim JS, Song HJ, Ko SK, Whang WK, Sohn UD. Quercetin-3-O-beta-d-glucuronopyranoside (QGC)induced HO-1 expression through ERK and PI3K activation in cultured feline esophageal epithelial cells. Fitoterapia . 2010;81(2):85-92.

54. Lee Y-J, Beak S-Y, Choi I, Sung J-S. Quercetin and its metabolites protect hepatocytes against ethanolinduced oxidative stress by activation of Nrf2 and AP-1. Food Sci Biotechnol . 2018;27(3):809-817.

55. Eblen ST. Extracellular-Regulated Kinases: Signaling From Ras to ERK Substrates to Control Biological Outcomes. Adv Cancer Res . 2018;138:99-142.

56. Das J, Ho M, Zikherman J, et al. Digital signaling and hysteresis characterize ras activation in lymphoid cells. Cell . 2009;136(2):337-351.

57. Banerjee P, Basu A, Datta D, Gasser M, Waaga-Gasser AM, Pal S. The heme oxygenase-1 protein is overexpressed in human renal cancer cells following activation of the Ras-Raf-ERK pathway and mediates anti-apoptotic signal. J Biol Chem . 2011;286(38):33580-33590.

58. Do MT, Kim HG, Khanal T, et al. Metformin inhibits heme oxygenase-1 expression in cancer cells through inactivation of Raf-ERK-Nrf2 signaling and AMPK-independent pathways. Toxicol Appl Pharmacol 
. 2013;271(2):229-238.

59. Hancock JT, Desikan R, Neill SJ. Role of reactive oxygen species in cell signalling pathways. Biochem Soc Trans . 2001;29(Pt 2):345-350.

60. Ray PD, Huang B-W, Tsuji Y. Reactive oxygen species (ROS) homeostasis and redox regulation in cellular signaling. Cell Signal . 2012;24(5):981-990.

61. Son Y, Cheong Y-K, Kim N-H, Chung H-T, Kang DG, Pae H-O. Mitogen-Activated Protein Kinases and Reactive Oxygen Species: How Can ROS Activate MAPK Pathways? J Signal Transduct . 2011;2011:792639.

62. Alvarez-Maqueda M, El Bekay R, Alba G, et al. 15-deoxy-delta 12,14-prostaglandin J2 induces heme oxygenase-1 gene expression in a reactive oxygen species-dependent manner in human lymphocytes. $J$ Biol Chem . 2004;279(21):21929-21937.

63. Chang S-H, Garcia J, Melendez JA, Kilberg MS, Agarwal A. Haem oxygenase 1 gene induction by glucose deprivation is mediated by reactive oxygen species via the mitochondrial electron-transport chain.Biochem $J$. 2003;371(Pt 3):877-885.

64. McCubrey JA, Steelman LS, Chappell WH, et al. Roles of the Raf/MEK/ERK pathway in cell growth, malignant transformation and drug resistance. Biochim Biophys Acta . 2007;1773(8):1263-1284.

65. Abe J, Berk BC. Fyn and JAK2 mediate Ras activation by reactive oxygen species. J Biol Chem . 1999;274(30):21003-21010.

66. Heim KE, Tagliaferro AR, Bobilya DJ. Flavonoid antioxidants: chemistry, metabolism and structureactivity relationships. J Nutr Biochem . 2002;13(10):572-584.

67. McNally SJ, Harrison EM, Ross JA, Garden OJ, Wigmore SJ. Curcumin induces heme oxygenase 1 through generation of reactive oxygen species, p38 activation and phosphatase inhibition. Int J Mol Med . 2007;19(1):165-172.

68. Laughton MJ, Halliwell B, Evans PJ, Hoult JR. Antioxidant and pro-oxidant actions of the plant phenolics quercetin, gossypol and myricetin. Effects on lipid peroxidation, hydroxyl radical generation and bleomycindependent damage to DNA. Biochem Pharmacol . 1989;38(17):2859-2865.

69. Dearman RJ, Kimber I. Differential stimulation of immune function by respiratory and contact chemical allergens. Immunology . 1991;72(4):563-570.

70. Farraj AK, Harkema JR, Kaminski NE. Allergic rhinitis induced by intranasal sensitization and challenge with trimellitic anhydride but not with dinitrochlorobenzene or oxazolone in A/J mice. Toxicol Sci Off $J$ Soc Toxicol . 2004;79(2):315-325.

71. Kaplan DH, Igyártó BZ, Gaspari AA. Early immune events in the induction of allergic contact dermatitis. Nat Rev Immunol . 2012;12(2):114-124.

72. Jenkins MK, Khoruts A, Ingulli E, et al. In vivo activation of antigen-specific CD4 T cells. Annu Rev Immunol . 2001;19:23-45.

\section{Figure legends}

Fig. 1. Effects of MQL on the OVA-induced allergic mouse model. (A) Experimental schedule of the OVAinduced allergic mouse model. Allergic immune responses in BALB/c mice were induced by i.p injection of OVA $(10 \mu \mathrm{g})$ with alum $(1 \mathrm{mg})$ on days 7 and days 14 . MQL was orally administered daily from day 7 to day 21. The level of (B) serum IgE was analyzed by ELISA. Splenocytes were seeded to $5 \times 10^{6} \mathrm{cells} / \mathrm{mL}$ and cultured in the presence of OVA $(100 \mu \mathrm{g} / \mathrm{mL})$ for $72 \mathrm{~h}$. (C) IL-4, (D) IL-5, (E) IL-13, and (F) IL-2 cytokines in culture supernatant of splenocytes were measured by ELISA. (G) Cell proliferation was measured by MTT assay, and (H) HO-1 expression was detected in splenocytes of each group by Western blot. Results 
are shown as mean $\pm \mathrm{SD}$. Asterisks $\left(^{*}\right)$ and $\left({ }^{* *}\right)$ indicate significant differences, at $\mathrm{p}<0.05$ and $\mathrm{p}<0.01$, respectively, between the MQL-treated and non-treated groups.

Fig. 2. Immunomodulatory effects of MQL on splenocytes of BALB/c mice immunized by OVA. Allergic immune responses in BALB/c mice were induced by i.p injection of OVA $(10 \mu \mathrm{g})$ with alum $(1 \mathrm{mg})$ on days 7 and days 14. Splenocytes were seeded to $5 \times 10^{6}$ cells $/ \mathrm{mL}$ and cultured in the presence or absence of OVA $(100 \mu \mathrm{g} / \mathrm{mL}$ ) and MQL for $72 \mathrm{~h}$. (A) IL-4, (B) IL-5, (C) IL-13, (D) IFN- $\gamma$, (E) IL-12, and (F) IL-2 cytokines in culture supernatant of splenocytes were measured by ELISA. (G) Cell proliferation was measured by MTT assay. (H) STAT1 and STAT6 phosphorylation and (I) HO-1 expression were detected by Western blot. Results are shown as mean $\pm \mathrm{SD}$. Asterisks $\left(^{*}\right)$ and $\left({ }^{*}\right)$ indicate significant differences, at $\mathrm{p}<0.05$ and $\mathrm{p}<0.01$, respectively, between the MQL-treated and non-treated groups.

Fig. 3. Effects of MQL on $\mathrm{CD}^{+} \mathrm{T}$ cell proliferation and HO-1 expression. CD4 ${ }^{+} \mathrm{T}$ cells isolated from splenocytes were seeded to $1 \times 10^{6}$ cells $/ \mathrm{mL}$ and cultured with anti-CD3 $(1 \mu \mathrm{g} / \mathrm{mL})$ and anti-CD28 antibodies $(1 \mu \mathrm{g} / \mathrm{mL})$. CD4 ${ }^{+} \mathrm{T}$ cells were cultured in the presence or absence of MQL for $48 \mathrm{~h}$. (A) IL-2 in culture supernatant of $\mathrm{CD} 4^{+} \mathrm{T}$ cells was measured by ELISA. (B) $\mathrm{CD} 4^{+} \mathrm{T}$ cell proliferation was measured by MTT assay. (C) Expression of p21 was detected by Western blot, and (D) cell cycle of CD4 ${ }^{+} \mathrm{T}$ cells was measured by flow cytometry. (E) HO-1 expression and (F) NRF2 nuclear translocation were detected in CD4 ${ }^{+} \mathrm{T}$ cell cultured in the presence or absence of MQL by Western blot. Results are shown as mean \pm SD. Asterisks $\left(^{*}\right)$ and $(* *)$ indicate significant differences, at $\mathrm{p}<0.05$ and $\mathrm{p}<0.01$ respectively, between the MQL-treated and non-treated groups.

Fig. 4. Effects of MQL on MAP kinase signaling pathways. (A) CD4 ${ }^{+} \mathrm{T}$ cells were isolated from splenocytes and pre-treated with U0126 $(5 \mu \mathrm{M})$, SB20350 $(5 \mu \mathrm{M})$, or SP600125 $(5 \mu \mathrm{M})$ for $1 \mathrm{~h}$ then treated with MQL for $24 \mathrm{~h}$ to detect HO-1 expression in CD4 ${ }^{+} \mathrm{T}$ cells. (B) To analyze MAPK phosphorylation induced by MQL, $\mathrm{CD}^{+} \mathrm{T}$ cells were pre-treated with MQL for $2 \mathrm{~h}$ before stimulation with anti-CD3 $(1 \mu \mathrm{g} / \mathrm{mL})$ and anti-CD28 antibodies $(1 \mu \mathrm{g} / \mathrm{mL})$. CD4 ${ }^{+} \mathrm{T}$ cells were treated with MQL for $2 \mathrm{~h}$ without stimulation, and (C) MAPK phosphorylation and (D) C-Raf phosphorylation were detected by Western blot. Data are representative of three independent experiments.

Fig. 5. Effects of MQL on ROS generation in $\mathrm{CD} 4^{+} \mathrm{T}$ cells. $\mathrm{CD} 4^{+} \mathrm{T}$ cells isolated from splenocytes were cultured in the presence or absence of MQL for $2 \mathrm{~h}$. Production of reactive oxygen species in CD4 ${ }^{+} \mathrm{T}$ cells was detected by using (A) DCFH-DA and (B) MitoSox ${ }^{\mathrm{TM}}$ Red and measured on a fluorescence plate reader or by flow cytometry. (C) $\mathrm{CD}^{+} \mathrm{T}$ cells isolated from splenocytes were pre-treated with NAC $(1 \mathrm{mg} / \mathrm{mL})$ for $1 \mathrm{~h}$ then cultured for $2 \mathrm{~h}$ in the presence of MQL. Phosphorylation of ERK and C-Raf were detected by Western blot. (D) $\mathrm{CD}^{+} \mathrm{T}$ cells were cultured with anti-CD3 $(1 \mu \mathrm{g} / \mathrm{mL})$ and anti-CD28 antibodies $(1$ $\mu \mathrm{g} / \mathrm{mL})$ for $24 \mathrm{~h}$ in the presence of NAC $(1 \mathrm{mg} / \mathrm{mL})$ and MQL. HO-1 expression in CD4 ${ }^{+} \mathrm{T}$ cells was detected by Western blot. Results are shown as mean \pm SD. Asterisks $\left(^{*}\right)$ and $\left(^{* *}\right)$ indicate significant differences, at $\mathrm{p}<0.05$ and $\mathrm{p}<0.01$, respectively, between the MQL-treated and non-treated groups.

Fig. 6. Effects of topical and oral administration on TMA-induced AD symptoms. (A) Experimental schedule of the TMA-induced AD-like mouse model with topical treatment of MQL. Cells from DLNs were seeded to $1 \times 10^{6}$ cells $/ \mathrm{mL}$ and cultured in the presence of Con A $(2 \mu \mathrm{g} / \mathrm{mL})$ for $48 \mathrm{~h}$. An experimental AD-like lesion was induced on the shaved flank skin of BALB/c mice by sensitization with $5 \%$ TMA $(50 \mu \mathrm{L})$ on day 0 then treated with $2 \%$ TMA $(10 \mu \mathrm{L})$ on days $5-14$. MQL $(4$ and $10 \mathrm{mg} / \mathrm{mL}, 10 \mu \mathrm{L})$ and Dex. $(1 \mathrm{mg} / \mathrm{mL}, 10$ $\mu \mathrm{L}$ ) were administered topically. (B) Ear swelling was measured $24 \mathrm{~h}$ after TMA treatment. (C) Infiltrating inflammatory cells in the ear tissues were stained using hematoxylin and eosin. The levels of (D) $\operatorname{IgE}$ in serum and (E) IL-13, (F) IFN- $\gamma$, and (G) IL-12 cytokines in culture supernatant of DLNs were measured by ELISA. (H) Experimental schedule of the TMA-induced AD-like mouse model with oral administration of MQL. An experimental AD-like lesion was induced on the shaved flank skin of BALB/c mice by sensitization with $5 \%$ TMA $(50 \mu \mathrm{L})$ on day 0 then treated with $2 \%$ TMA $(20 \mu \mathrm{L})$ on days $5,8,11,14,17,20,23$, and 26. MQL (4 and $10 \mathrm{mg} / \mathrm{kg}$ ) and Dex. (1 mg/kg) were administrated by orally from day 5 to day 26 . (I) Ear swelling was measured $24 \mathrm{~h}$ after TMA treatment. (J) Infiltrating inflammatory cells in the ear tissues were stained using hematoxylin and eosin. The levels of (K) IgE in serum and (L) IL-13, (M) IFN- $\gamma$, and 
(N) IL-12 cytokines in culture supernatant of DLNs were measured by ELISA. Results are shown as mean \pm SD. Asterisks $(*)$ and $(* *)$ indicate significant differences, at $\mathrm{p}<0.05$ and $\mathrm{p}<0.01$, respectively, between the MQL-treated and non-treated groups of TMA-treated mice.
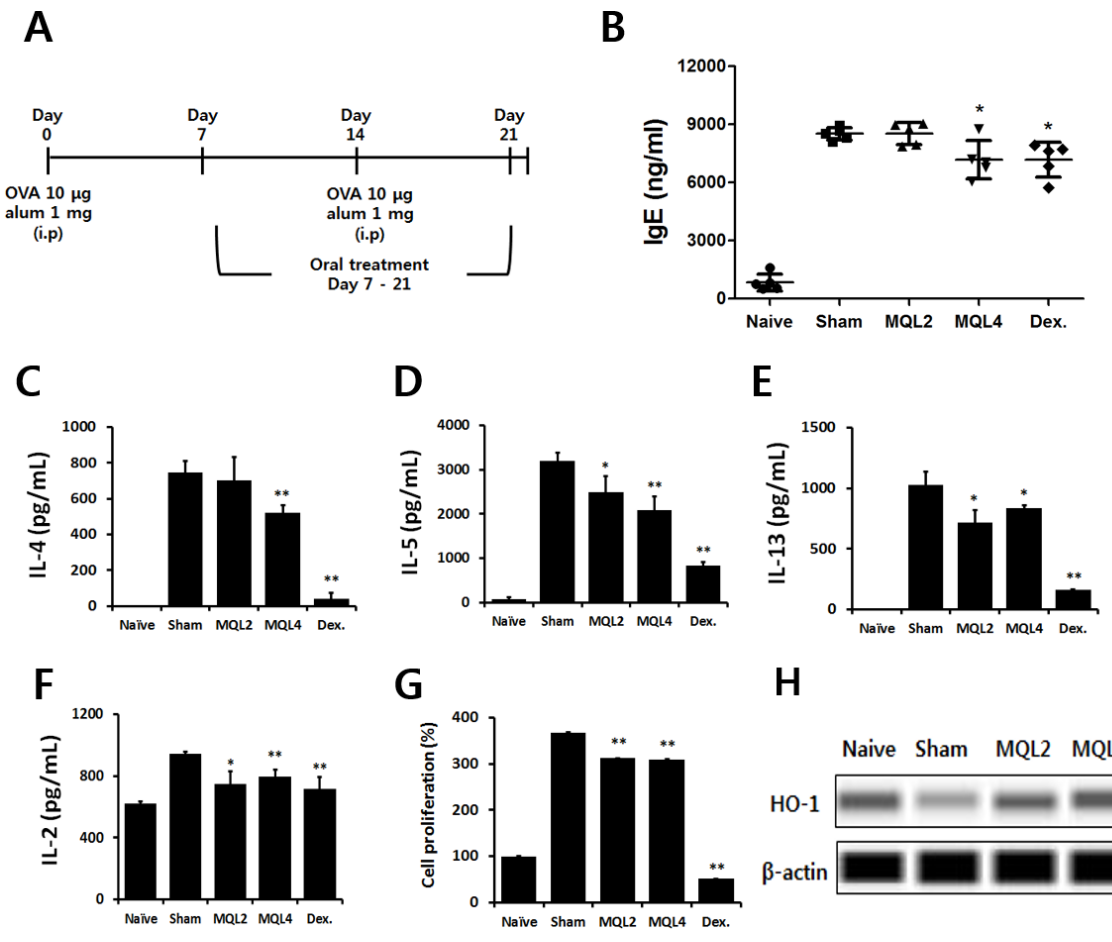

H

Figure 1

Figure 2
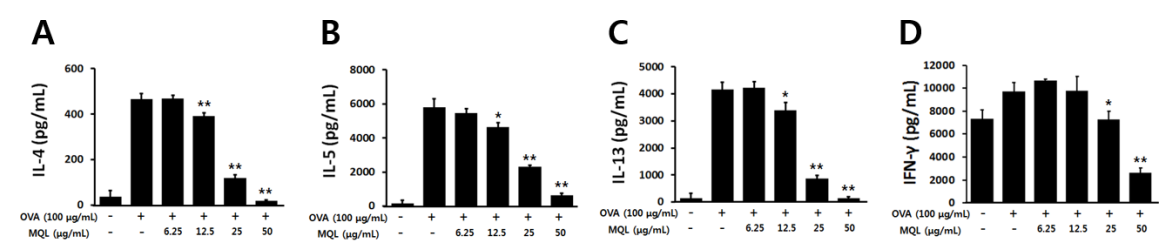

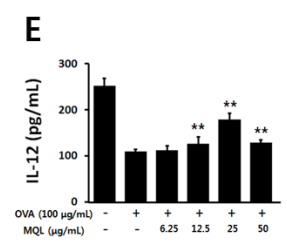

H

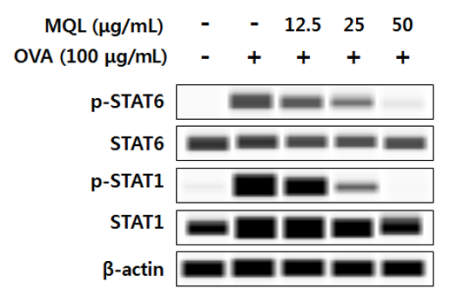

$\mathrm{F}$
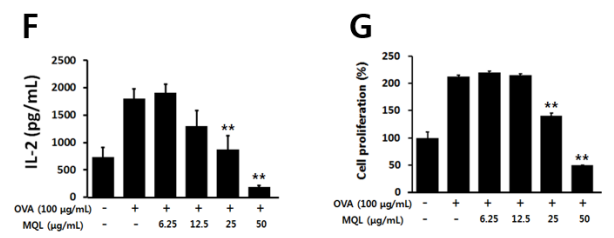

I

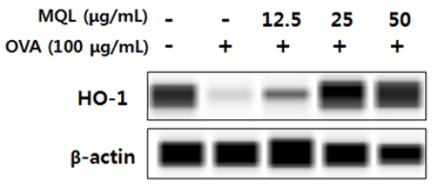


Figure 3

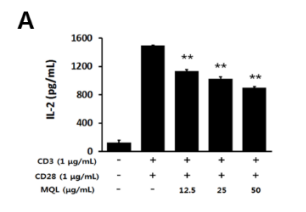

B



D

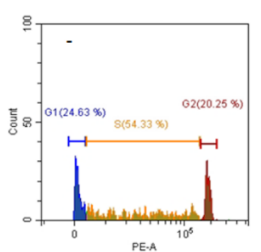

PE:A

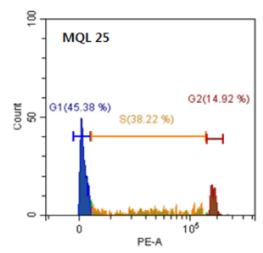

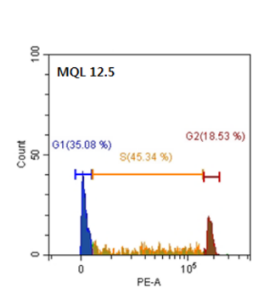

E

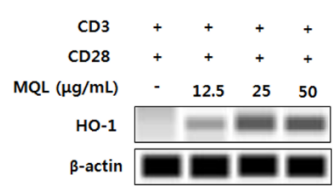

$\mathbf{F}$



Figure 4

A



B

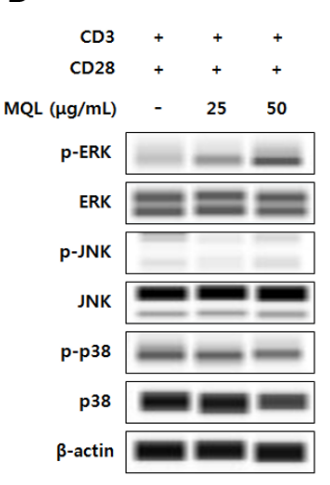

C

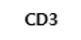

CD28

MQL $(\mu \mathrm{g} / \mathrm{mL}) \quad-\quad 25 \quad 50$

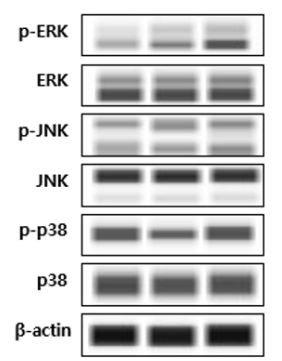

D

MQL ( $(\mathrm{g} / \mathrm{mL}) \quad-\quad 25 \quad 50$
p-c-Raf
C-Raf
$\beta$-actin

Figure 5 


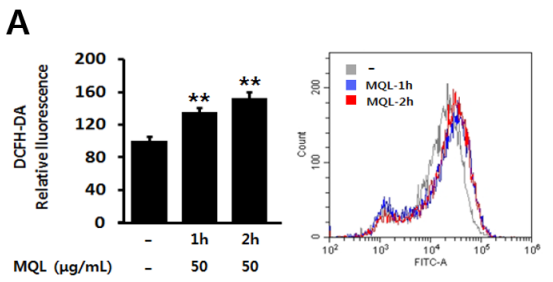

C

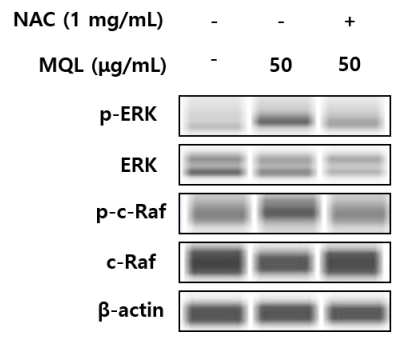

B

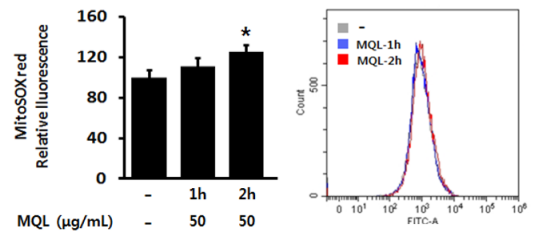

D



Figure 6

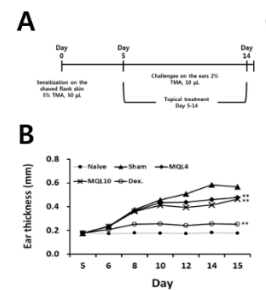

C

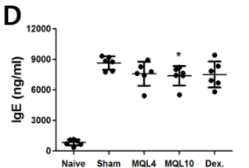

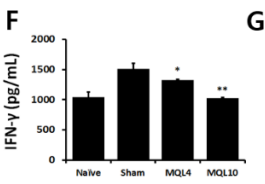
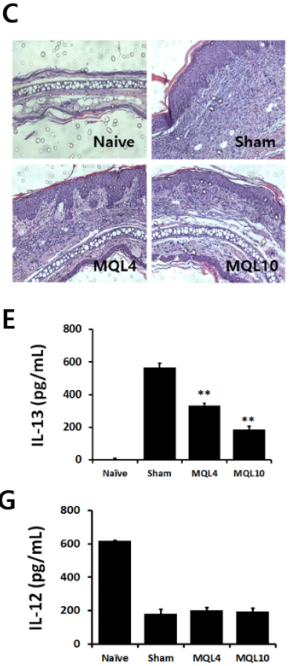
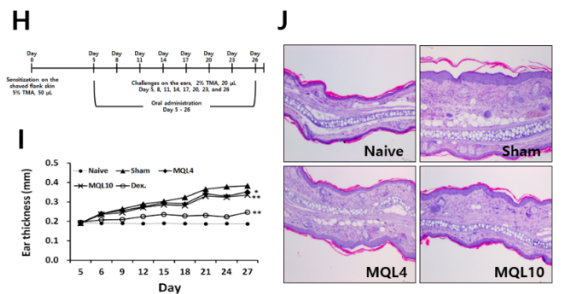



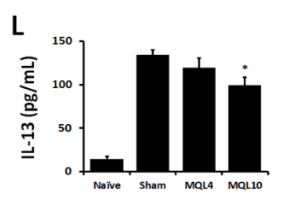

M

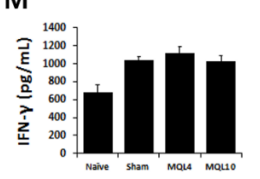

$\mathrm{N}$

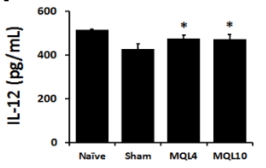


A

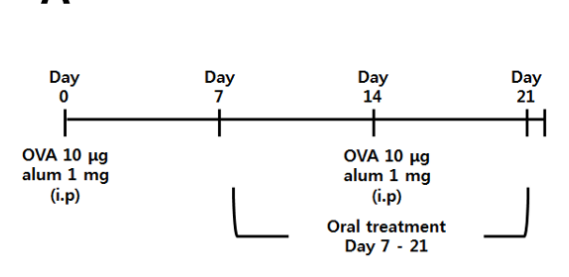

C

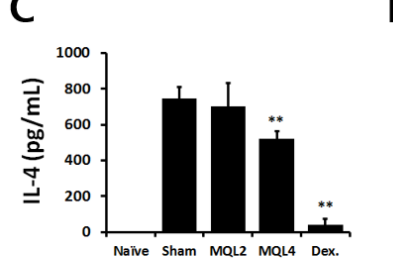

F

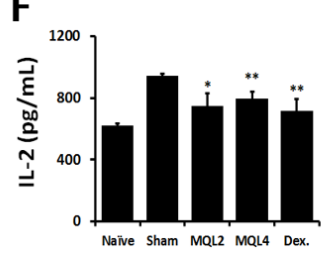

D

G
B

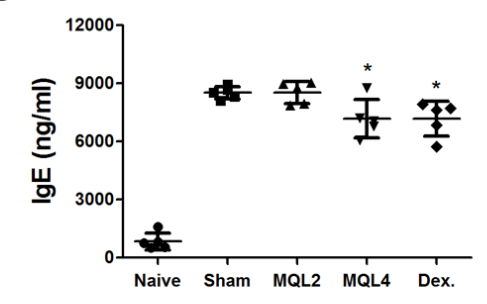

E
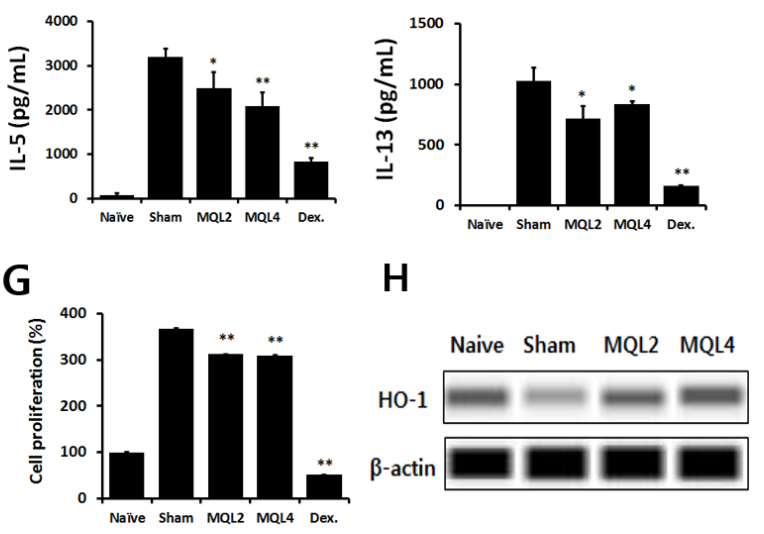

Elli.

ill.

c

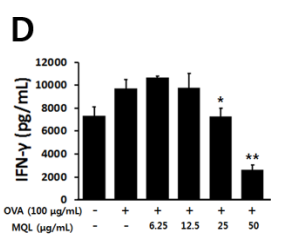

$\mathrm{E}$

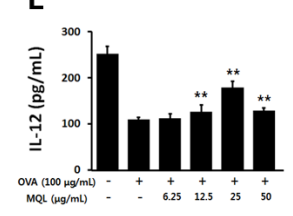

H

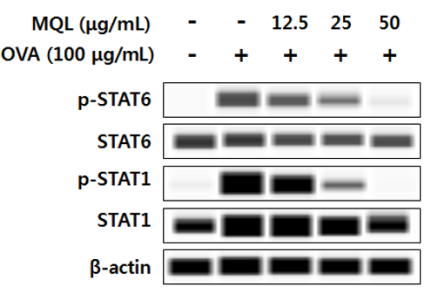

F G

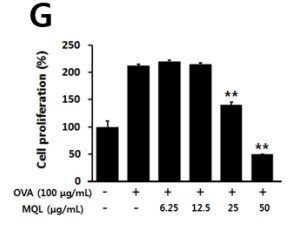

I



HO-1

$\beta$-actin 
A<smiles>[SiH3]</smiles>

B

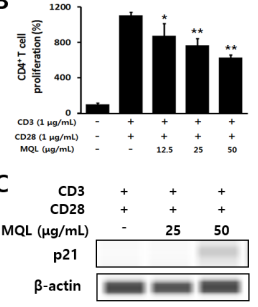

D
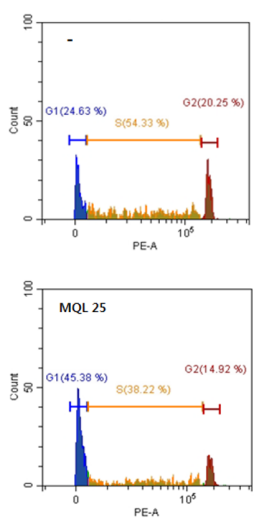
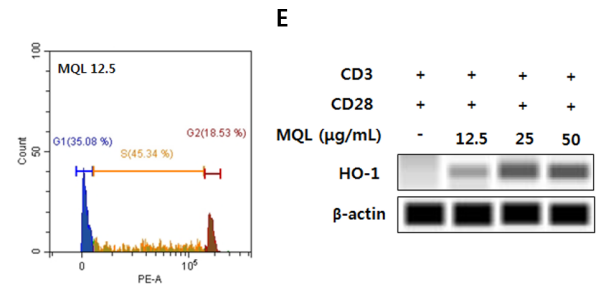

$\mathbf{F}$

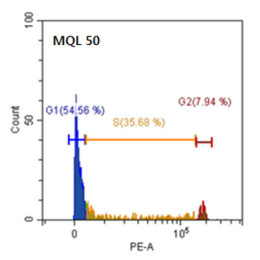

A

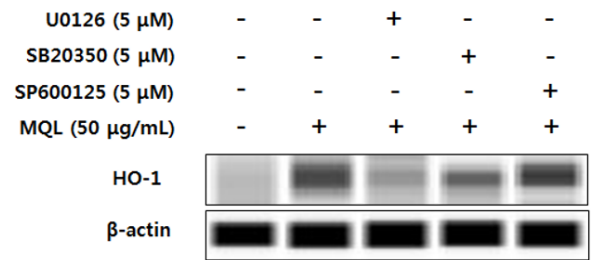

B

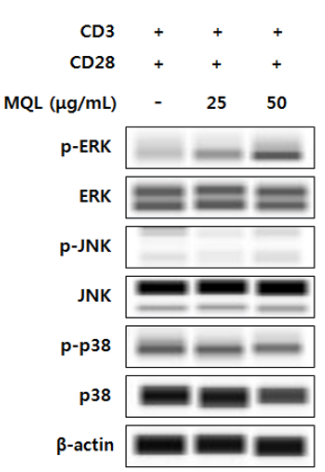

C

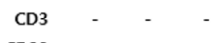

MQL $(\mu \mathrm{g} / \mathrm{mL}) \quad-\quad 25 \quad 50$

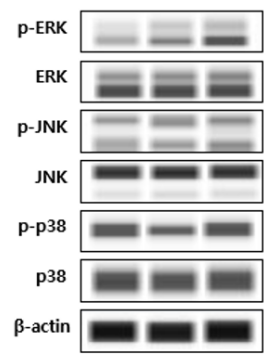

D

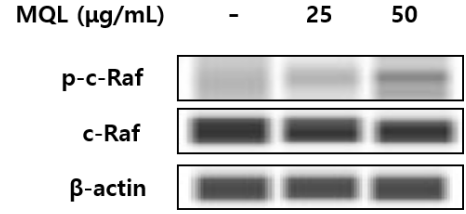


A

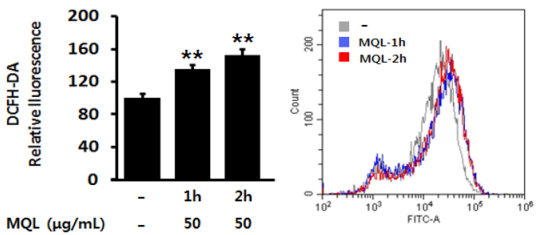

C

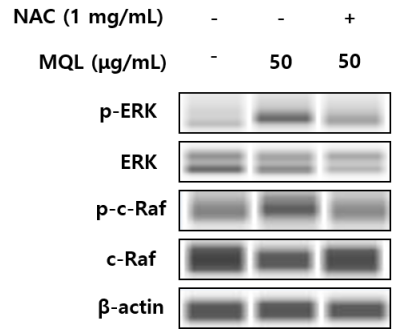

B

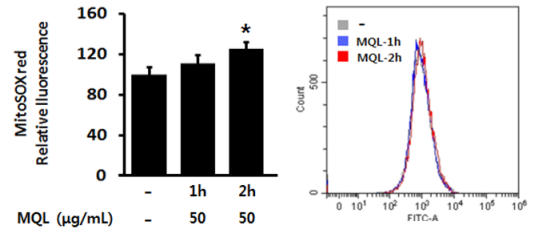

D



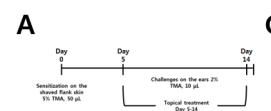

B

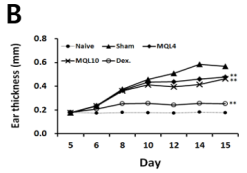

$D_{12000}$

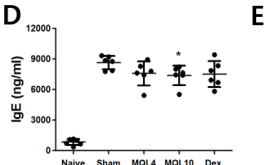

F

E
C
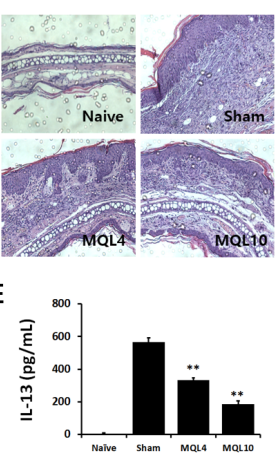

II..
H

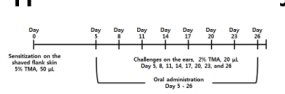

I

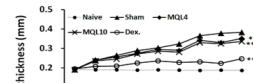

0.3
5
5

K

$\mathbf{M}$ 